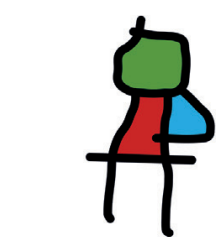

SEICAIP

\section{Allergologia et immunopathologia}

Sociedad Española de Inmunología Clínica, Alergología y Asma Pediátrica

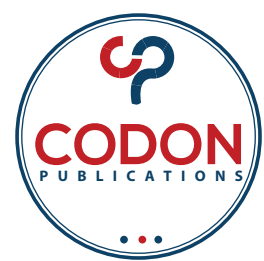

SERIES

OPEN ACCESS (c)

\title{
Prospective observational study on the characteristics of eosinophilic esophagitis in southeast Spain
}

\section{$M^{\mathrm{a}}$ Araceli Castro Jiménez ${ }^{\mathrm{a} *}$, Fernando Florido López ${ }^{\mathrm{b}}, \mathrm{M}^{\mathrm{a}}$ José Rojas Vilchez ${ }^{\mathrm{b}}$, Alejandro Raúl Gratacós Gómez ${ }^{\mathrm{c}}, \mathrm{M}^{\mathrm{a}}$ Ángeles Lara Jiménez ${ }^{\mathrm{b}}$, Rosa Garcia Rodriguez $^{\mathrm{d}}$, Elisa Gómez Torrijos ${ }^{d}$}

aHospital Universitario "Virgen de las Nieves," Granada, Spain

"Hospital Universitario "San Cecilio," Granada, Spain

'Facultad de Medicina, Universidad de Castilla La Mancha, Ciudad Real, Spain

${ }^{d}$ Allergy Section, Hospital General Universitario, Ciudad Real, Spain

Received 23 January 2021; Accepted 2 February 2021

Available online 1 July 2021

\section{KEYWORDS \\ choking; \\ dysphagia; \\ eosinophil; \\ eosinophilic \\ esophagitis; \\ oesophagoscopy}

\begin{abstract}
Introduction: Eosinophilic esophagitis (EoE) is a chronic esophageal atopic disease because sensitization to aeroallergens and foods allergens is very common.

Objectives: This study is the first work that studies multiple characteristics of EoE in the southeast of Spain to know whether EoE in the patients of this region is similar to that of other regions of Spain in terms of demography, symptoms, and atopic characteristics.

Method: It is an observational prospective study of patients diagnosed with EoE at Granada (Spain). We recorded demographic data (age, sex, and personal history of atopy), clinical data (impaction and dysphagia), allergologic data (prick test and specific immunoglobulin E) to foods, aeroallergen, and pan-allergens, and other endoscopic-histologic data and comorbidities.

Results: The demographic, allergologic, and endoscopic characteristics of patients with EoE in Granada were similar to the rest of Spain, except the higher frequency of sensitization to olive pollen, food allergy, and anaphylaxis reactions.

Conclusions: The higher frequency of sensitization to olive pollen and food allergy with severe clinical manifestations (anaphylaxis) in patients with EoE in Granada could have a negative impact on patients' quality of life.

(c) 2021 Codon Publications. Published by Codon Publications.
\end{abstract}

*Corresponding author: $M^{a}$ Araceli Castro Jiménez, Hospital Universitario "Virgen de las Nieves," Granada, Spain. Email address: aracelicast82@hotmail.com 


\section{Introduction}

Eosinophilic esophagitis (EoE) is a chronic esophageal disease characterized clinically by symptoms of esophageal dysfunction, and histologically by eosinophilic inflammation. ${ }^{1}$ Other systemic and local causes must be ruled out. Clinical manifestations and histopathology data should be interpreted jointly rather than separately. ${ }^{2}$ EoE is currently considered an atopic disease, since sensitization to aeroallergens and foods allergens is quite common. ${ }^{2,3}$

\section{Objective}

The objective of this study was to determine the demographic, clinical, allergologic, analytic, endoscopic, and histologic characteristics and comorbidities in a series of patients with EoE.

\section{Materials and Methods}

We performed an observational prospective study of patients diagnosed with $\mathrm{EoE}^{2}$ at Complejo Hospital ariode Granada (Spain) between November 2018 and May 2019. The hospital had a catchment population of 602,230 inhabitants.

We used an Excel spreadsheet to record demographic data (age, sex, and personal history of atopy), clinical data (impaction and dysphagia) and allergologic data (prick test and specific immunoglobulin $E$ [slgE] to the most frequently involved foods in EoE [milk, cereals, egg, nuts, legumes, and fish], aeroallergen and pan-allergens such as lipid transfer protein [LTP] and profilin). We also recorded laboratory data (eosinophilic cationic protein [ECP], total lgE [tlgE] and eosinophils in peripheral blood), endoscopic data, histologic data and comorbidities (atopic dermatitis, rhinoconjunctivitis, bronchial asthma, allergy to inhaled allergens, and allergy to foods [anaphylaxis, urticaria/ angioedema, and oral allergy syndrome]).

The prick tests were performed using commercial extracts (Alk-Abelló, Madrid, Spain; Leti, Barcelona, Spain) according to the recommendations of the European Academy of Allergy and Clinical Immunology, with a positive histamine control $(10 \mathrm{mg} / \mathrm{mL})$ and a negative saline control. Results were considered positive if the wheal was $\geq 3 \mathrm{~mm}$, eosinophil values $>0.55 \times 10^{3} / \mathrm{Ml}$, and total white cells > $5.50 \%$ were considered high. Levels of tIgE and slgE were determined using ImmunoCAP (Thermo Fisher Scientific, Uppsala, Sweden); tlgE > $100 \mathrm{kU} / \mathrm{L}$ and $\mathrm{slgE}>0.34 \mathrm{kU} / \mathrm{L}$ were considered high. ECP > $10 \mathrm{ng} / \mathrm{mL}$ determined using enzymelinked immunoassay (CUSABIO) was considered high.

Qualitative variables were reported as frequencies, and quantitative variables were reported as averages and standard deviations (SD). This study was approved by the Provincial Ethics Committee of Granada (Supplementary Figure S1).

\section{Results (Table 1)}

We recruited 31 patients. Most of them were young adult men, and more than a half of them had a history of atopy.
The main symptom was food impaction, and not dysphagia, which was much less frequent.

More than $70 \%$ of patients were atopic. Sensitization to foods was high (two-thirds in the present series). LTP was the most prevalent food allergen in more than one-third of the series, closely followed by milk, legumes, and nuts. More than half of the patients were sensitized to aeroallergens, the most prevalent being olive pollen.

According to biomarkers, the average value of blood eosinophil count was high in more than a quarter of patients. The percentage of eosinophils and tlgE was high in more than half of patients, and ECP was high in $>85 \%$ of patients.

Endoscopic study revealed a predominance of pseudorings. Histology revealed basal cell hyperplasia, eosinophilic granules, and dilatation of intercellular spaces in all patients.

Anaphylaxis was the most frequent comorbidity, very closely followed by rhinitis. More than one-third of the patients had bronchial asthma. Atopic dermatitis was the least frequent comorbidity.

\section{Discussion}

In this report, the average age and personal history of atopy were similar to those reported in other studies. ${ }^{2,5}$ Male patients were more frequent in our series (2:1). It was slightly lower than reported in other studies because of low number of patients. ${ }^{6-9}$ Food impaction was more common than found in other studies. ${ }^{5}$ It could probably be due to the longer course of EoE.

Sensitization was more common to food allergens than to aeroallergens, in contrast to other studies with adult patients. ${ }^{5-8}$ This result would justify the high rate of LTP sensitization and anaphylaxis in the present study. ${ }^{10}$ Findings for the most prevalent food allergens-LTP, nuts, and legumeswere similar to those for Central Spain. ${ }^{5-7}$ However, sensitization to cow's milk was more common in our patients than in the rest of Spain..$^{5-8}$ It is worth highlighting the sensitization to olive pollen in aeroallergens because it was notably more frequent than grass-pollen sensitization, even though other reports show the opposite..$^{6-8}$ This was due to the aerobiology of the living areas of the patients.

In laboratory, percentage of eosinophils was higher than reported in another study, ${ }^{8}$ and ECP was also high in most of the patients. These findings could be related with the presence of concomitant atopic diseases in our patients. ${ }^{5,8}$ Our histologic findings were similar to other findings, ${ }^{6}$ although they were higher for basal cell hyperplasia. ${ }^{8,9}$ The endoscopic findings of our patients were similar to those of other studies, but the presence of pseudo-rings was higher. ${ }^{5,6,8}$ This shows a stenosing phenotype caused by the long-term EoE.

More than half of the patients in the present study were atopic. ${ }^{1,2,5}$ The geographic distribution of allergy to LTP and cross-reactivity in areas of high pollen exposure ${ }^{10}$ could explain secondary sensitization to nuts and legumes. ${ }^{2,3,6}$ The high rate of anaphylaxis found could be due to food allergens and LTP sensitization in patients having EoE in Granada. ${ }^{2,7}$ There was no evidence of involvement of LTP in EoE. Nevertheless, cow's milk was the most involved 
Table 1 Demographic, clinical, endoscopic, histologic, and allergologic characteristics.

\begin{tabular}{|c|c|c|c|c|c|}
\hline Demographic data & $\mathrm{N}$ & $\%$ & & & \\
\hline Age: mean (SD) & 31 & $35.4 \pm 12.7$ & & & \\
\hline Gender: Men-women (n, \%) & 31 & $21 ; 67.7 \%-10 ; 32.23 \%$ & & & \\
\hline Personal history of atopy (n, \%) & 31 & $21 ; 67.7 \%$ & & & \\
\hline $\begin{array}{l}\text { Evaluation by the allergology } \\
\text { department }(n, \%)\end{array}$ & 31 & $23 ; 74.2 \%$ & & & \\
\hline \multicolumn{6}{|l|}{ Clinical data } \\
\hline Impaction (n, \%) & 29 & $19 ; 65.51 \%$ & & & \\
\hline Dysphagia (n, \%) & 29 & $2 ; 6.89 \%$ & & & \\
\hline \multicolumn{6}{|l|}{ Comorbidities } \\
\hline \multicolumn{6}{|l|}{ Food allergy } \\
\hline -Anaphylaxis & 31 & $19 ; 61.3 \%$ & & & \\
\hline -OAS/urticaria & 28 & $6 ; 21.43 \%$ & & & \\
\hline Rhinitis and/or conjunctivitis & 28 & $16 ; 57.14 \%$ & & & \\
\hline Asthma & 28 & $11 ; 39.28 \%$ & & & \\
\hline Atopic dermatitis & 28 & $3 ; 10.71 \%$ & & & \\
\hline \multicolumn{6}{|l|}{ Laboratory parameters } \\
\hline Mean (SD) eosinophil count & 25 & $0.438 \pm 0.25\left(\times 10^{3}\right)$ & & & \\
\hline Mean (SD) eosinophil percentage & 25 & $5.76 \pm 3.05$ & & & \\
\hline Mean (SD) lgE level (kU/L) & 12 & $177.08 \pm 162.51$ & & & \\
\hline Mean (SD) ECP level (IU) & 7 & $63.7 \pm 37.9$ & & & \\
\hline \multicolumn{6}{|l|}{ Endoscopy findings } \\
\hline Rings and/or trachealization & 28 & $24 ; 85,71 \%$ & & & \\
\hline Furrows or striae & 28 & $10 ; 35,71 \%$ & & & \\
\hline Stenosis & 28 & $1 ; 3,57 \%$ & & & \\
\hline \multicolumn{6}{|l|}{ Histology findings } \\
\hline Microabscess & 20 & $10 ; 50 \%$ & & & \\
\hline Hyperplasia & 19 & $19 ; 100 \%$ & & & \\
\hline Granules & 20 & $20 ; 100 \%$ & & & \\
\hline Fibrosis & 9 & $6 ; 66.66 \%$ & & & \\
\hline \multicolumn{6}{|l|}{ Allergologic characteristics } \\
\hline Sensitization to aeroallergens* & $\mathrm{N}$ & $\%(\mathrm{~N}=23)$ & Sensitization to foods* & $\mathrm{N}$ & $\%(N=23)$ \\
\hline$(\mathrm{n}, \%)$ & 14 & 60.8695 & $(\mathrm{n}, \%)$ & 17 & $73.9130 \%$ \\
\hline Olive & 12 & 52.17 & Milk and fractions & 7 & $30.4346 \%$ \\
\hline Grasses & 8 & 30.4346 & Egg and fractions & 6 & $26.0869 \%$ \\
\hline Artemisia & 6 & 26.0868 & Cereals (wheat, corn) & 5 & $21.7391 \%$ \\
\hline Parietaria & 4 & 17.3912 & & & \\
\hline Salsola & 4 & 17.3912 & Legumes (lentils, beans, peas) & 7 & $30.4346 \%$ \\
\hline Mites & 3 & 13.0434 & Nuts (peanut, hazelnut, walnut) & 7 & $30.4346 \%$ \\
\hline Alternaria & 6 & 26.0868 & Shellfish and fish & 0 & 0 \\
\hline Cat & 7 & 30.4346 & Lipid transfer protein & 8 & $34.7824 \%$ \\
\hline Horse & 3 & 13.0434 & Profilin & 3 & $13.0434 \%$ \\
\hline
\end{tabular}

ECP: eosinophilic cationic protein; IgE: immunoglobulin E; SD: standard deviation.

*Sensitization (TC and lgE).

food in this disease, ${ }^{1,2}$ followed by wheat and legumes. ${ }^{10}$ Bronchial asthma and especially rhinoconjunctivitis are frequent comorbidities in patients with EoE. ${ }^{5}$ Besides, patients with EoE, especially children, are more likely to suffer from food and respiratory allergies. ${ }^{5}$

Our study was limited with low number of patients, non-randomized selection, and lack of studies from Andalucía. However, it provided new data from a Spanish region that was different from others in terms of pollination and allergy sensitization.

\section{Conclusions}

Overall, the demographic, allergologic, and endoscopic characteristics of patients with EoE in a sanitary district of Granada are similar to those found in the rest of Spain, except the higher frequency of sensitization to olive pollen and food allergy with severe clinical manifestations (anaphylaxis) and a slight predominance of the stenosing endoscopic phenotype. These differences could impact negatively patients' quality of life. 


\section{Acknowledgments}

We are grateful to Hospital Universitario Virgen de las Nieves and Hospital Clínico San Cecilio, this study would not have been possible without their help.

No specific grants were received for this study from public sector agencies, the commercial sector, or nonprofit bodies.

\section{Statement of Ethics}

Subjects have given their written informed consent and the study protocol was approved by the Provincial Ethics Committee of Granada.

\section{Conflicts of Interest}

The authors declare that they have no conflicts of interest.

\section{Author contributions}

ACJ, FFL, JRV, and ALJ did consultation and diagnosis of patients. ACJ did recruitment of patients, study their characteristics, and carried out statistical work. RGG searched bibliography and translated the paper from Spanish to English. EGT did designing and writing of the manuscript. RGR did the general review of the study and checked its English language.

\section{References}

1. González-Cervera J, Lucendo AJ. Eosinophilic esophagitis: An evidence-based approach to therapy. J Investig Allergol Clin Immunol 2016;26(1):8-18. https://doi.org/10.18176/jiaci.0002

2. Lucendo AJ, Molina-Infante J, Arias Á, Von Arnim U, Bredenoord AJ, Bussmann C, et al. Guidelines on eosinophilic esophagitis: Evidence-based statements and recommendations for diagnosis and management in children and adults. United Eur Gastroenterol J 2017;5(3):335-58. https://doi. org/10.1177/2050640616689525

3. Watts MM, Saltoun C, Greenberger PA. Eosinophilic esophagitis. Allergy Asthma Proc 2019;40(6):462-4. https://doi. org/10.2500/aap.2019.40.4272

4. He YT, Christos PJ, Reisacher WR. Airborne and food sensitization patterns in children and adults with eosinophilic esophagitis. Int Forum Allergy Rhinol 2018;8(5):571-6. https://doi. org/10.1002/alr.22095

5. Reed CC, Dellon ES. Eosinophilic esophagitis. Med Clin North Am 2019;103(1):29-42. https://doi.org/10.1016/j. mcna.2018.08.009

6. Molina-Infante J, Martin-Noguerol E, Alvarado-Arenas M, Porcel-Carreño SL, Jimenez-Timon S, Hernandez-Arbeiza FJ. Selective elimination diet based on skin testing has suboptimal efficacy for adult eosinophilic esophagitis. J Allergy Clin Immunol 2012;130(5):1200-2. https://doi.org/10.1016/j. jaci.2012.06.027

7. Castro Jiménez A, Gómez Torrijos E, García Rodríguez R, FeoBrito F, BorjaSegade J, Galindo Bonilla PA, et al. Demographic, clinical and allergological characteristics of Eosinophilic Esophagitis in a Spanish central region. Allergol Immunopathol (Madr) 2014;42(5):407-14. https://doi. org/10.1016/j.aller.2013.04.004

8. Gómez Torrijos E, Rodriguez Sanchez J, Castro Jimenez A, Garcia Rodriguez R, Feo-Brito F, Molina-Infante J. Proton pump inhibitor-responsive oesophageal eosinophilia (PPIREE): Characteristics of a Spanish population in central Spain. Clin Exp Allergy 2015;45(8):1367-9. https://doi.org/10.1111/ cea.12581

9. Gómez Torrijos E, Sánchez Miranda P, Donado Palencia P, Castro Jimenez A, Rodriguez Sánchez J, Mendez Díaz Y, et al. Eosinophilic Esophagitis: Demographic, clinical, endoscopic, histologic, and atopic characteristics of children and teenagers in a region in central Spain. J Investig Allergol Clin Immunol 2017;27(2):104-10. https://doi.org/10.18176/jiaci.0112

10. Ojeda $P$, Ibáñez MD, Olaguibel JM, Sastre J, Chivato T. Alergológica 2015: A national survey on allergic diseases in the Spanish pediatric population. J Investig Allergol Clin Immunol 2018;28(5):321-9. https://doi.org/10.18176/jiaci.0308 